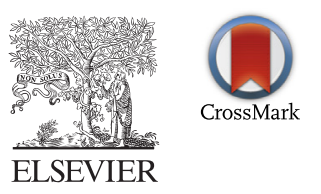

\title{
Review
}

\section{Exercise Testing and Stress Imaging in Valvular Heart Disease}

\author{
Christine Henri, MD, ${ }^{\mathrm{a}, \mathrm{b}}$ Luc A. Piérard, MD, PhD, ${ }^{\mathrm{b}}$ Patrizio Lancellotti, MD, PhD, ${ }^{\mathrm{b}}$ \\ François-Pierre Mongeon, MD, ${ }^{a}$ Philippe Pibarot, DVM, PhD, ${ }^{\mathrm{c}}$ and \\ Arsène J. Basmadjian, MD, MSc ${ }^{\mathrm{a}}$ \\ ${ }^{a}$ Research Centre and Department of Medicine, Montreal Heart Institute, Université de Montréal, Montréal, Québec, Canada \\ ${ }^{b}$ Heart Valve Clinic, University of Liège, Department of Cardiology, Sart Tilman University Hospital, Liège, Belgium \\ 'Québec Heart and Lung Institute, Québec, Québec, Canada
}

\begin{abstract}
The role of exercise testing and stress imaging in the management of patients with valvular heart disease (VHD) is reviewed in this article. The American College of Cardiology/American Heart Association and the European Society of Cardiology/European Association of Cardiothoracic Surgery have recently put emphasis on the role of exercise testing to clarify symptom status and the use of stress imaging to assess the dynamic component of valvular abnormalities and unmask subclinical myocardial dysfunction that could be missed at rest. Recent studies have demonstrated the incremental prognostic value of exercise echocardiography for asymptomatic patients with severe aortic stenosis, moderate-severe mitral stenosis, and severe primary mitral
\end{abstract}

Transthoracic echocardiography at rest is the preferred method for noninvasive evaluation of valvular heart disease (VHD) because recommendations for surgery are based mainly on the development of symptoms and hemodynamic repercussions on the left ventricle (LV). Nevertheless, the dynamic component of VHD, which is influenced by loading conditions and ventriculo-arterial coupling and subclinical myocardial dysfunction, could be missed at rest. Stress imaging is useful because it addresses clinical responses during exercise testing combined with assessment of the dynamic changes in valvular and ventricular function. Moreover, in patients with low-flow, low-gradient aortic stenosis (AS), dobutamine stress echocardiography (DSE) is recommended to differentiate true severe AS from pseudosevere AS. ${ }^{1,2}$ The purpose of this article is to describe the role of exercise testing

Received for publication December 16, 2013. Accepted March 12, 2014.

Corresponding author: Dr Arsène J. Basmadjian, Montreal Heart Institute, 5000 Bélanger Street, Montreal, Québec H1T 1C8, Canada. Tel.: +1-514376-3330; fax: +1-514-376-1355.

E-mail: arsene.basmadjian@icm-mhi.org

See page 1023 for disclosure information.

\section{RÉSUMÉ}

Le rôle de l'épreuve d'effort et de l'imagerie à l'effort dans la prise en charge des patients ayant une cardiopathie valvulaire (CV) est passé en revue dans cet article. Le American College of Cardiology et la American Heart Associaton ainsi que la Société Européenne de Cardiologie et l'Association Européenne de Chirurgie Cardio-Thoracique ont récemment souligné le rôle de l'épreuve d'effort pour élucider l'état symptomatique, et l'utilisation de l'imagerie à l'effort pour évaluer la composante dynamique des anomalies valvulaires et découvrir la dysfonction myocardique sous-clinique qui pourrait ne pas être observé au repos. De récentes études ont démontré la valeur pronostique différentielle de l'échocardiographie à l'effort des patients

and stress imaging, mostly echocardiography, in the management of patients with VHD.

\section{Exercise Protocols}

Exercise testing is the first choice over pharmacological stress for risk stratification of asymptomatic VHD patients. By decreasing preload and afterload, pharmacological stress with dobutamine has limited utility, except in patients with AS and low LV ejection fraction (LVEF). ${ }^{3}$ Safety of exercise testing has been demonstrated and complications remain low, especially in the semisupine position with a lower risk of hemodynamic collapse compared with treadmill. ${ }^{4,5}$ A comprehensive clinical evaluation to rule out the presence of symptoms and to identify potential contraindications is essential before undergoing exercise testing. Contraindications to exercise testing include: clear indications for valve surgery (ie, symptomatic severe AS or mitral stenosis [MS], uncontrolled hypertension or arrhythmias, physical/mental disability, or systemic disease with the inability to adequately exercise). ${ }^{6}$ A symptom-limited exercise test performed under supervision with the goal of reaching at least $85 \%$ of the age-predicted heart rate is recommended. Patients should continue taking their usual medication(s), 
regurgitation. In patients with low-flow, low-gradient aortic stenosis, dobutamine stress echocardiography is recommended to differentiate true severe from pseudosevere aortic stenosis. Data on the prognostic value of stress echocardiography in aortic regurgitation and functional mitral regurgitation are less robust. Data are sparse on the use of stress imaging in right-sided VHD, however recent studies using stress cardiovascular magnetic resonance imaging offer some prognostic information. Although the strongest recommendations for surgical treatment continue to be based on symptom status and resting left ventricular repercussions, stress imaging can be useful to optimize risk stratification and timing of surgery in VHD. Randomized clinical trials are required to confirm that clinical decision-making based on stress imaging can lead to improved outcomes.

because abnormal exercise testing results while patients are taking suboptimal therapy might be confusing for management decisions.

Exercise stress echocardiography (ESE) in VHD should be performed by an experienced sonographer or cardiologist. Treadmill or semisupine bicycle exercise testing can be performed. Treadmill exercise is more commonly used in North America and is realized according to the American College of Cardiology/American Heart Association (ACC/ AHA) practice guidelines using a modified Bruce protocol. ${ }^{7}$ However, this technique allows imaging only after exercise, limiting the accuracy of measurements. In contrast, semisupine ergocycle with a tilting table, which is the preferred approach in Europe, is more physiologic and permits optimal image acquisition during each step of exercise testing. ${ }^{3}$

Blood pressure, heart rate, 12-lead electrocardiography, and echocardiographic parameters related to the valve, the LV, asymptomatiques atteints d'une sténose aortique grave, d'une sténose mitrale modérée à grave et de régurgitation mitrale primaire grave. Chez les patients atteints d'une sténose aortique à faible gradient et à bas débit, l'échocardiographie avec dobutamine est recommandée pour différencier la véritable sténose aortique sévère de la sténose aortique aortique pseudosévère. Les données sur la valeur pronostique de l'échocardiographie à l'effort lors de régurgitation aortique et de régurgitation mitrale fonctionnelle sont moins fiables. Les données sur l'utilisation de l'imagerie à l'effort lors de CV du côté droit sont rares. Cependant, de récentes études utilisant l'imagerie par résonance magnétique cardiovasculaire offrent certaines informations sur le pronostic. Bien que les meilleures recommandations de traitement chirurgical soient encore fondées sur l'état symptomatique et les répercussions au repos du ventricule gauche, l'imagerie à l'effort peut être utile pour optimiser la stratification du risque et le moment de la chirurgie lors de CV. Des essais cliniques aléatoires sont nécessaires pour confirmer si la prise de décision clinique fondée sur l'imagerie à l'effort entraîne l'amélioration des résultats.

and the hemodynamic consequences (eg, pulmonary arterial pressure) are recorded at rest, at each step of the exercise test and during recovery (Table 1). The workload should be adjusted for each patient (ie, beginning at $50 \mathrm{~W}$ with an increase of $25 \mathrm{~W}$ every 2 minutes for a young patient with preserved LV function vs starting at $25 \mathrm{~W}$ with an increase of $10 \mathrm{~W}$ every 2 minutes for an older patient with low LVEF). Symptoms should be assessed regularly during the examination. Exercise testing should be interrupted when the target heart rate is reached or if the patient presents typical chest pain, limiting breathlessness, dizziness, hypotension (decrease in systolic blood pressure $\geq 20 \mathrm{~mm} \mathrm{Hg}$ ), significant ventricular arrhythmia, or muscular exhaustion. The test is considered positive if the patient encounters $\geq 1$ of the following criteria: angina, limiting dyspnea, syncope or nearsyncope, $\geq 2 \mathrm{~mm}$ horizontal or downsloping ST segment depression, decrease or $<20 \mathrm{~mm} \mathrm{Hg}$ increase in systolic blood pressure, or complex ventricular arrhythmias. ${ }^{6}$

Table 1. Exercise stress echocardiography protocol according to valvular heart disease

\begin{tabular}{|c|c|c|c|}
\hline \multirow[b]{2}{*}{ Baseline } & Aortic stenosis & Mitral stenosis & Mitral regurgitation \\
\hline & \multicolumn{3}{|c|}{ Complete resting echocardiography* } \\
\hline $25 \mathrm{~W}$ & $\begin{array}{l}\text { Mean aortic gradient } \\
\text { Aortic valve area } \\
\text { CW aortic valve } \\
\text { PW LV outflow tract } \\
\text { SPAP } \\
\text { CW TR jet } \\
\text { E/Ea ratio } \\
\text { PW mitral inflow } \\
\text { TDI PW mitral annulus }\end{array}$ & $\begin{array}{l}\text { Mean mitral gradient } \\
\text { CW mitral valve } \\
\text { SPAP } \\
\text { CW TR jet }\end{array}$ & $\begin{array}{l}\text { EROA, RVol } \\
\text { PISA radius } \\
\text { CW MR jet } \\
\text { SPAP } \\
\text { CW TR jet }\end{array}$ \\
\hline Each $25 \mathrm{~W}$ increment and at peak & $\begin{array}{l}\text { Mean aortic gradient } \\
\text { Aortic valve area } \\
\text { SPAP }\end{array}$ & $\begin{array}{l}\text { Mean mitral gradient } \\
\text { SPAP }\end{array}$ & $\begin{array}{l}\text { EROA, RVol } \\
\text { SPAP }\end{array}$ \\
\hline
\end{tabular}

LV function: 2-dimensional grey-scale images in 4, 2, and 3 chamber views ( $>60$ FPS)

CW, continuous-wave Doppler; EROA, effective regurgitant orifice area; FPS, frame per second; LV, left ventricle; MR, mitral regurgitation; PISA, proximal isovelocity surface area; PW, pulsed-wave Doppler; RVol, regurgitant volume; SPAP, systolic pulmonary artery pressure; TDI, tissue Doppler imaging; TR, tricuspid regurgitation.

* With emphasis on parameters listed at $25 \mathrm{~W}$.

${ }^{\dagger}$ Measured before $\mathrm{E}$ and $\mathrm{A}$ wave fusion. 


\section{Aortic Stenosis}

\section{Exercise testing}

AS is a highly and increasingly prevalent condition which has become a major health concern. ${ }^{8}$ Characteristically, patients present a long latent asymptomatic period in which the risk of sudden death is low, even with severe AS (ie, peak aortic velocity $\geq 4 \mathrm{~m} / \mathrm{s}$, mean transaortic gradient [MTAG] $\geq$ $40 \mathrm{~mm} \mathrm{Hg}$, and aortic valve area $[\mathrm{AVA}] \leq 1.0 \mathrm{~cm}^{2}$ or $\leq 0.60$ $\mathrm{cm}^{2} / \mathrm{m}^{2}$ ). However, the risk of sudden death increases dramatically when symptoms appear, justifying the class I recommendation for aortic valve replacement (AVR). ${ }^{1,2,9}$ Symptomatic status can be difficult to establish, especially in elderly patients, because they might minimize or deny their symptoms or reduce their level of physical activity to avoid them. Exercise testing can be useful to unmask symptoms in patients with severe AS. Approximately one-third of patients who claim to be asymptomatic develop symptoms with exercise testing. ${ }^{10,11}$ For this reason, exercise testing is strongly advocated by the European Society of Cardiology/European Association of Cardiothoracic Surgery (ESC/EACTS) (class I recommendation $)^{2}$ whereas the ACC/AHA suggest that it might be considered (class IIa recommendation) in asymptomatic patients with severe AS. ${ }^{1}$ However, interpretation of exercise testing could be limited in the elderly population. Positive predictive value in patients $>70$ years old has been shown to be significantly lower than in younger patients $(56 \%$ compared with 79\%), with similar negative predictive values. ${ }^{11}$ According to this, a negative exercise test in an elderly patient is reassuring, but a positive exercise test might lack in specificity because of frequent comorbidities.

Symptom-limited stress testing, with appropriate supervision and monitoring, has been demonstrated to be safe in severe AS and to add important prognostic value. ${ }^{12}$ An exercise test is considered normal if the patient remains asymptomatic (no angina, limiting dyspnea at low workload [ie, during the first steps of exercise], syncope or near-syncope) during the test with an adequate increase in systolic blood pressure $(>20 \mathrm{~mm}$ $\mathrm{Hg}$ ) and absence of complex ventricular arrhythmias. A positive exercise test has been shown to predict the rapid onset of symptoms and cardiac death. ${ }^{10}$ Dizziness has the highest positive predictive value for the development of symptoms during the following year. The occurrence of rapidly reversible dyspnea at high workloads should, however, not be interpreted as abnormal. Of note, ST-depression $(>2 \mathrm{~mm}$, horizontal or downsloping) during exercise with AS does not seem to improve the predictive accuracy of the test, particularly in patients with concomitant coronary artery disease (CAD). ${ }^{1}$

\section{Exercise stress echocardiography}

Changes in mean aortic gradient. Asymptomatic patients with severe AS and normal LV function undergoing early AVR might have better outcomes than those with medical treatment. ${ }^{13}$ However, although AVR is safe and widely performed, the rates of operative mortality and valve-related complications are not null. Therefore, the identification of prognostic factors could help to determine the patients who might benefit the most from early elective surgery. ESE has demonstrated an additive prognostic value over clinical findings, resting echocardiography, and exercise testing. An increase in MTAG by $\geq 18-20 \mathrm{~mm} \mathrm{Hg}$ (Fig. 1) was associated with an increased risk of cardiac-related events. ${ }^{14,15}$ This increase in MTAG most likely reflects the presence of a more severe AS with a noncompliant, rigid aortic valve (Table 2). ${ }^{16}$

Changes in LV function. Assessment of LV function during exercise also provides incremental prognostic information. Limited contractile reserve (ie, a decrease or a limited increase in LVEF) is associated with an abnormal hemodynamic response to exercise, development of symptoms, and cardiovascular death. ${ }^{17,18}$ Exercise-induced LV dysfunction might represent a more advanced disease state. This could be explained by afterload mismatch and exercise-exhausted coronary flow reserve leading to subendocardial ischemia and more extensive myocardial fibrosis. ${ }^{25}$ Standard LVEF measurements are insensitive to detect early forms of LV systolic dysfunction. Assessment of longitudinal LV function seems to be a more powerful parameter in predicting the occurrence of symptoms, exercise intolerance, and outcomes in AS. ${ }^{26,27}$ Longitudinal function can be studied using tissue Doppler imaging with pulsed-wave Doppler at the mitral annulus measuring Sa velocities or using 2-dimensional speckle tracking analyzing global longitudinal strain (GLS). Donal et al. reported that LV contractile reserve assessed with GLS is predominantly altered in patients with an abnormal exercise test (Table 2). ${ }^{19}$

Left ventricular filling pressure estimation and systolic pulmonary artery pressure. Other findings might explain the occurrence of symptoms in patients with severe AS, such as increase of LV filling pressure or systolic pulmonary artery pressure (SPAP) with exercise. At rest, a cutoff value of the ratio of early diastolic mitral inflow velocity to early diastolic annulus velocity $(\mathrm{E} / \mathrm{Ea})>13$ has been reported to identify an $\mathrm{LV}$ end-diastolic pressure $>15 \mathrm{~mm} \mathrm{Hg}$ with a sensitivity of $93 \%$ and a specificity of $88 \%$ in moderate-severe AS. ${ }^{28}$ Exercise values have yet to be validated in AS patients. Of note, $\mathrm{E} / \mathrm{Ea}$ ratio should be measured before $\mathrm{E}$ and $\mathrm{A}$ wave fusion, which appear at high heart rates.

Pulmonary hypertension (PHT) could be unmasked with ESE (Fig. 1). In a recent prospective study, exercise-induced PHT, defined as SPAP $>60 \mathrm{~mm} \mathrm{Hg}$, was associated with a 2 -fold increased risk of cardiac events at 3-year follow-up in asymptomatic patients with severe AS and preserved LVEF (Table 2).

\section{Impact on clinical decision-making}

- Current ESC/EACTS and ACC/AHA guidelines recommend AVR in asymptomatic patients with severe AS who present symptoms during exercise testing (ESC/ EACTS, class I; ACC/AHA, class IIa) or a decrease in blood pressure below baseline (ESC/EACTS, class IIa; ACC/AHA, class IIa)..$^{1,2}$

- The ESC/EACTS recently added recommendation for AVR based on ESE, such as the increase of MTAG by $>20 \mathrm{~mm} \mathrm{Hg}$ during exercise (class IIb). ${ }^{2}$

- ESE might be useful to improve risk stratification and identify patients who might benefit from early surgery. Prospective clinical trials are needed to support the use of exercise-induced echocardiographic changes, such as increase in MTAG, limited LV contractile reserve, or PHT as clear indications for AVR (Fig. 2A). 


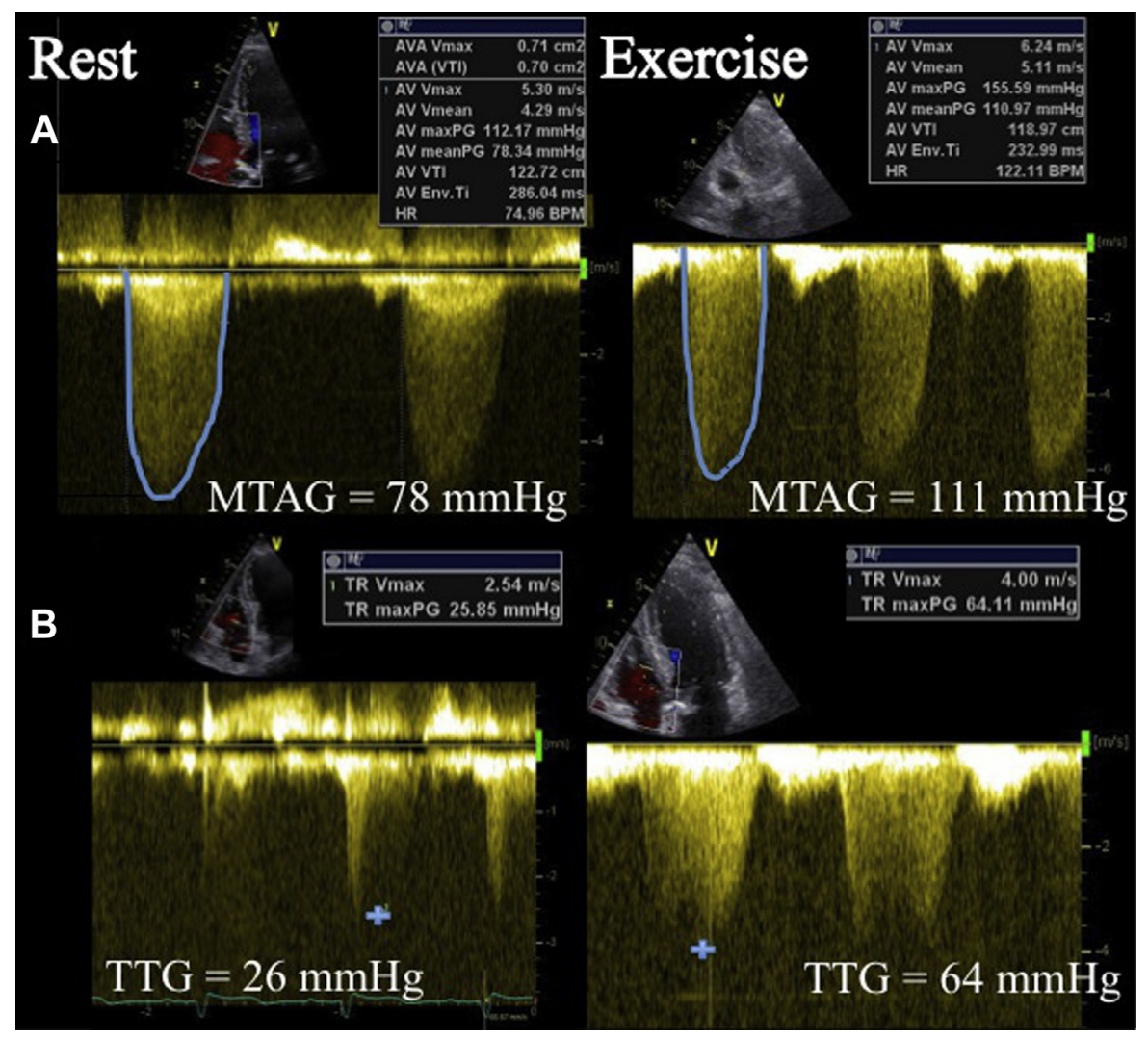

Figure 1. Doppler findings in an asymptomatic severe aortic stenosis patient at rest (left panels) and at exercise (right panels). A significant increase of MTAG $\geq 20 \mathrm{~mm} \mathrm{Hg}(\mathbf{A})$ and exercise-induced PHT (B) are shown, which represent 2 risk factors for cardiac events. AV, aortic valve; AVA, AV area; AV Env. Ti, aortic time interval; HR, heart rate; maxPG, maximal pressure gradient; meanPG, mean pressure gradient; MTAG, mean transaortic gradient; PHT, pulmonary hypertension; TR, tricuspid regurgitation; TTG, transtricuspid gradient; Vmax, maximal velocity; Vmean, mean velocity; VTI, velocity time integral.

\section{Low-Flow, Low-Gradient AS}

\section{Dobutamine stress echocardiography}

According to guidelines, "Low-flow, low-gradient AS" with LV dysfunction is defined as a small AVA $\left(<1.0 \mathrm{~cm}^{2}\right.$ or $<0.6$ $\left.\mathrm{cm}^{2} / \mathrm{m}^{2}\right)$ with low MTAG $(<30-40 \mathrm{~mm} \mathrm{Hg})$, low LVEF $(<40 \%)$ and low flow state (stroke volume index $<35 \mathrm{~mL} /$ $\left.\mathrm{m}^{2}\right) .{ }^{1,2}$ This condition is observed in approximately $5 \%-10 \%$ of patients with severe AS and can correspond to 2 different situations: true severe AS with depressed LVEF caused by excessive afterload and concomitant myocardial disease, or pseudosevere AS with myocardial contractile dysfunction leading to reduced valve opening. ${ }^{29}$ DSE has been demonstrated to be useful to differentiate true severe from pseudosevere AS and to assess the presence and extent of flow reserve. ${ }^{30-33}$ Flow reserve is calculated as follows: flow reserve $(\%)=\left(\mathrm{SV}_{\text {peak }}-\mathrm{SV}_{\text {rest }}\right) / \mathrm{SV}_{\text {rest }} \times 100$ where SV (stroke volume) $=0.785 \times$ LVOT (left ventricular outflow tract) diameter $^{2} \times$ LVOT TVI, respectively, at rest and at peak stress. DSE is a class IIa indication for this purpose according to the current ESC/EACTS and ACC/AHA guidelines. ${ }^{1,2}$ The main objective of DSE is to increase the transvalvular flow rate using a low-dose protocol with gradual increments of dobutamine $(5 \mu \mathrm{g} / \mathrm{kg} / \mathrm{min})$ at $5-8$ minute intervals to achieve a steady state and avoid tachyarrhythmia or ischemia. ${ }^{3}$ The end points for terminating infusion of dobutamine are: (1) heart rate $>220-$ age; (2) systolic blood pressure $<80 \mathrm{~mm} \mathrm{Hg}$ or $>220 \mathrm{~mm} \mathrm{Hg}$; (3) ischemia detected using electrocardiogram (> $5 \mathrm{~mm}$ flat or downsloping ST depression); (4) complex ventricular arrhythmias or rapid new atrial arrhythmias; (5) breathlessness, angina, dizziness, or syncope; and (6) maximum dose reached $(20 \mu \mathrm{g} / \mathrm{kg} / \mathrm{min}){ }^{34-36}$

True severe vs pseudosevere AS. True severe AS (Fig. 3) is defined as an increase in MTAG to $>40 \mathrm{~mm} \mathrm{Hg}$, a small change in AVA (increase $<0.3 \mathrm{~cm}^{2}$ ) and/or an AVA $\leq 1.0$ $1.2 \mathrm{~cm}^{2}$, and particularly the presence of flow reserve (ie, $>$ $20 \%$ increase of stroke volume) with low-dose dobutamine. ${ }^{2}$ Presence of both criteria (true AS and presence of flow reserve) will help to identify patients who will benefit the most from AVR in terms of long-term survival and improvement of functional status. ${ }^{32}$ Pseudosevere AS is characterized by a significant increase in AVA (increase $\geq 0.3 \mathrm{~cm}^{2}$ ) and/or an AVA $>1.2 \mathrm{~cm}^{2}$, and an MTAG remaining $<40 \mathrm{~mm} \mathrm{Hg}$, explained by the recruitment of LV myocytes leading to greater opening of the "not severely" stenotic aortic valve with low-dose dobutamine. The prevalence of pseudosevere AS is considered to be between $20 \%$ and $30 \%$ of patients with lowflow, low-gradient AS. ${ }^{29}$ These patients should be treated with aggressive heart failure therapy and they might require AVR if medical therapy fails to improve their condition and/or if the stenosis progresses to the severe stage. ${ }^{37}$ 
Table 2. Main studies addressing exercise echocardiography in asymptomatic patients with aortic stenosis or primary mitral regurgitation and preserved LV function

\begin{tabular}{|c|c|c|c|c|c|}
\hline Type of study & Patient $\mathrm{n}$ & Inclusion criteria & End points & Predictors of outcome & Referen \\
\hline \multicolumn{6}{|l|}{ Aortic stenosis } \\
\hline $\begin{array}{l}\text { Prospective } \\
\mathrm{FU}=15 \pm 7 \text { months }\end{array}$ & 69 & $\mathrm{AVA} \leq 1 \mathrm{~cm}^{2}$ & $\begin{array}{l}\text { Occurrence of symptoms, heart failure, } \\
\text { AVR, cardiac death }\end{array}$ & $\begin{array}{l}\text { Exercise-induced increase in MTAG } \geq \\
18 \mathrm{~mm} \mathrm{Hg}\end{array}$ & 14 \\
\hline $\begin{array}{l}\text { Prospective } \\
\text { FU }=20 \pm 14 \text { months }\end{array}$ & 186 & $\begin{array}{l}\text { AVA }<1.5 \mathrm{~cm}^{2} \\
\text { AVAi }<0.9 \mathrm{~cm}^{2} / \mathrm{m}^{2}\end{array}$ & Occurrence of AVR or cardiac death & $\begin{array}{l}\text { Exercise-induced increase in MTAG > } \\
20 \mathrm{~mm} \mathrm{Hg}\end{array}$ & 15 \\
\hline Prospective & 128 & $\mathrm{AVA} \leq 1 \mathrm{~cm}^{2}$ & Abnormal exercise test & $\begin{array}{l}\text { Exercise-induced increase in MTAG } \geq \\
17 \mathrm{~mm} \mathrm{Hg} \text { and decrease in LVEF }\end{array}$ & 17 \\
\hline $\begin{array}{l}\text { Prospective } \\
\mathrm{FU}=11 \text { months }\end{array}$ & 50 & $\mathrm{AVA} \leq 1 \mathrm{~cm}^{2}$ & Occurrence of symptoms or AVR & Exercise-induced decrease in LVEF & 18 \\
\hline Case-control & 207 & $\mathrm{AVA} \leq 1.2 \mathrm{~cm}^{2}$ & Abnormal exercise test & $\begin{array}{l}\text { Higher exercise increases in MTAG } \\
\text { and smaller changes in LV GLS }\end{array}$ & 19 \\
\hline $\begin{array}{l}\text { Prospective } \\
\mathrm{FU}=19 \pm 11 \text { months }\end{array}$ & 105 & AVAi $<0.6 \mathrm{~cm}^{2} / \mathrm{m}^{2}$ & $\begin{array}{l}\text { Occurrence of AVR or cardiovascular } \\
\text { death }\end{array}$ & $\begin{array}{l}\text { Exercise-induced PHT (SPAP > } \\
\quad 60 \mathrm{~mm} \mathrm{Hg})\end{array}$ & 20 \\
\hline \multicolumn{6}{|l|}{ Mitral regurgitation } \\
\hline $\begin{array}{l}\text { Prospective } \\
\mathrm{FU}=22 \pm 13 \text { months }\end{array}$ & 61 & $\begin{array}{l}\text { EROA }>20 \mathrm{~mm}^{2} \text { and } \\
\quad \mathrm{RVol}>30 \mathrm{~mL}\end{array}$ & Occurrence of symptoms & $\begin{array}{l}\text { Exercise-induced increase in EROA > } \\
10 \mathrm{~mm}^{2} \text { and } \mathrm{RVol}>15 \mathrm{~mL}\end{array}$ & 21 \\
\hline $\begin{array}{l}\text { Prospective } \\
\mathrm{FU}=19 \pm 14 \text { months }\end{array}$ & 78 & $\begin{array}{c}\mathrm{EROA}>20 \mathrm{~mm}^{2} \text { and } \\
\mathrm{RVol}>30 \mathrm{~mL}\end{array}$ & Occurrence of symptoms & $\begin{array}{l}\text { Exercise-induced PHT (SPAP > } \\
56 \mathrm{~mm} \mathrm{Hg})\end{array}$ & 22 \\
\hline $\begin{array}{l}\text { Prospective } \\
\mathrm{FU}=27 \pm 15 \text { months }\end{array}$ & 196 & $\begin{array}{l}\mathrm{EROA}>20 \mathrm{~mm}^{2} \text { and } \\
\mathrm{RVol}>30 \mathrm{~mL}\end{array}$ & Occurrence of MVR & $\begin{array}{l}\text { Exercise-induced RV dysfunction } \\
\text { (TAPSE }<19 \mathrm{~mm} \text { ) and exercise } \\
\text { PHT (SPAP }>54 \mathrm{mmH} \text { ) }\end{array}$ & 23 \\
\hline $\begin{array}{l}\text { Prospective } \\
\text { FU }=24 \pm 21 \text { months }\end{array}$ & 115 & $\begin{array}{c}\mathrm{EROA}>20 \mathrm{~mm}^{2} \text { and } \\
\mathrm{RVol}>30 \mathrm{~mL}\end{array}$ & $\begin{array}{l}\text { Occurrence of MVR, cardiac death, } \\
\text { heart failure }\end{array}$ & $\begin{array}{l}\text { Exercise-induced increase of LV GLS } \\
\quad<2 \%\end{array}$ & 24 \\
\hline
\end{tabular}

AVA, aortic valve area; AVAi, indexed aortic valve area; AVR, aortic valve replacement; EROA, effective regurgitant orifice area; FU, follow-up; GLS, global longitudinal strain; LV, left ventricular; LVEF, left ventricular ejection fraction; MTAG, mean transaortic gradient; MVR, mitral valve replacement; PHT, pulmonary hypertension; RV, right ventricular; RVol, regurgitant volume; SPAP, systolic pulmonary artery pressure; TAPSE, tricuspid annular plane systolic excursion.

\begin{abstract}
Absence of flow reserve. Absence of flow reserve, defined as an increase $<20 \%$ of stroke volume using low-dose dobutamine, is present in $30 \%-40 \%$ of patients with a low flow state and could be explained by afterload mismatch (imbalance between AS severity and myocardial reserve), myocardial fibrosis, or concomitant $\mathrm{CAD} .{ }^{29}$ Patients without flow reserve present much greater operative mortality (22\%-32\%) during AVR than those with flow reserve $(5 \%-8 \%) .{ }^{29,32,38}$ Moreover, lack of flow reserve has been identified as a predictor for surgical and 30-day mortality. ${ }^{32}$ Despite high surgical mortality, 5-year mortality was significantly lower after AVR (31\%) compared with medical therapy alone $(87 \%)$ in patients without flow reserve. ${ }^{38}$ Also, the lack of flow reserve could not reliably predict the absence of LVEF recovery after surgery because $65 \%$ of patients with no flow reserve had a postoperative increase in LVEF of $>10 \% .{ }^{39}$ According to these data, absence of flow reserve should not be considered an absolute contraindication for AVR. ${ }^{38,39}$ Nevertheless, in patients without flow reserve, stenosis severity often remains indeterminate at the outset of DSE and another imaging modality, such as aortic calcification quantification using computed tomography, might be needed to confirm stenosis severity and indication for surgery. ${ }^{40,41}$
\end{abstract}

Projected AVA. A limitation of DSE is that the increase in transvalvular flow achieved might vary widely from patient to patient. Hence, interpretation of the AVA and MTAG changes without consideration of the relative change in transvalvular flow might lead to ambiguous results. A way to overcome this limitation is to compare AVA at a standardized mean transvalvular flow rate (Q) of $250 \mathrm{~mL} / \mathrm{s}$. This novel parameter, called the projected AVA $\left(\mathrm{AVA}_{\mathrm{proj}}\right)$, has been shown to be more closely related to actual AS severity and survival than traditional DSE parameters. The $\mathrm{AVA}_{\text {proj }}$ is calculated as follows: $\mathrm{AVA}_{\text {proj }}=\left(\mathrm{AVA}_{\text {peak }}-\mathrm{AVA}_{\text {rest }}\right) /$ $\left(\mathrm{Q}_{\text {peak }}-\mathrm{Q}_{\text {rest }}\right) \times\left(250-\mathrm{Q}_{\text {rest }}\right)+\mathrm{AVA}_{\text {rest }}$, where $A V A_{\text {rest }}$ and $\mathrm{Q}_{\text {rest }}$, and $A V A_{\text {peak }}$ and $\mathrm{Q}_{\text {peak }}$ are AVA calculated by continuity equation and $\mathrm{Q}$ by dividing $\mathrm{SV}(\mathrm{mL})$ by $\mathrm{LV}$ ejection time (s) at rest and at peak DSE, respectively. ${ }^{34,35,42}$ An $\mathrm{AVA}_{\text {proj }} \leq 1.0 \mathrm{~cm}^{2}$ is considered to be severe.

\section{Impact on clinical decision-making}

- In symptomatic patients with low-flow, low-gradient AS and low LVEF, AVR is recommended after the demonstration using DSE of true severe AS with evidence of flow reserve (ESC/EACTS, class IIa; ACC/ AHA, class IIa). ${ }^{1,2}$

- AVR might also be considered in true severe AS patients without flow reserve after careful evaluation of other comorbidities, particularly CAD (ESC/EACTS, class IIb; ACC/AHA, class IIa). ${ }^{2}$

- Initial medical therapy with close follow-up is preferred in patients with pseudosevere AS. ${ }^{37}$ Surgery could be reconsidered if there is no clinical improvement or if deterioration occurs. The importance of the imbalance between the degree of AS severity and myocardial dysfunction should be regularly assessed and AVR might be considered, arguing that moderate AS could have a similar hemodynamic effect on a failing $L V$ as a severe AS on a preserved LV. In cases of severe myocardial impairment, cardiac transplantation might be considered an option in selected patients (Fig. 2B). ${ }^{29}$ 
A

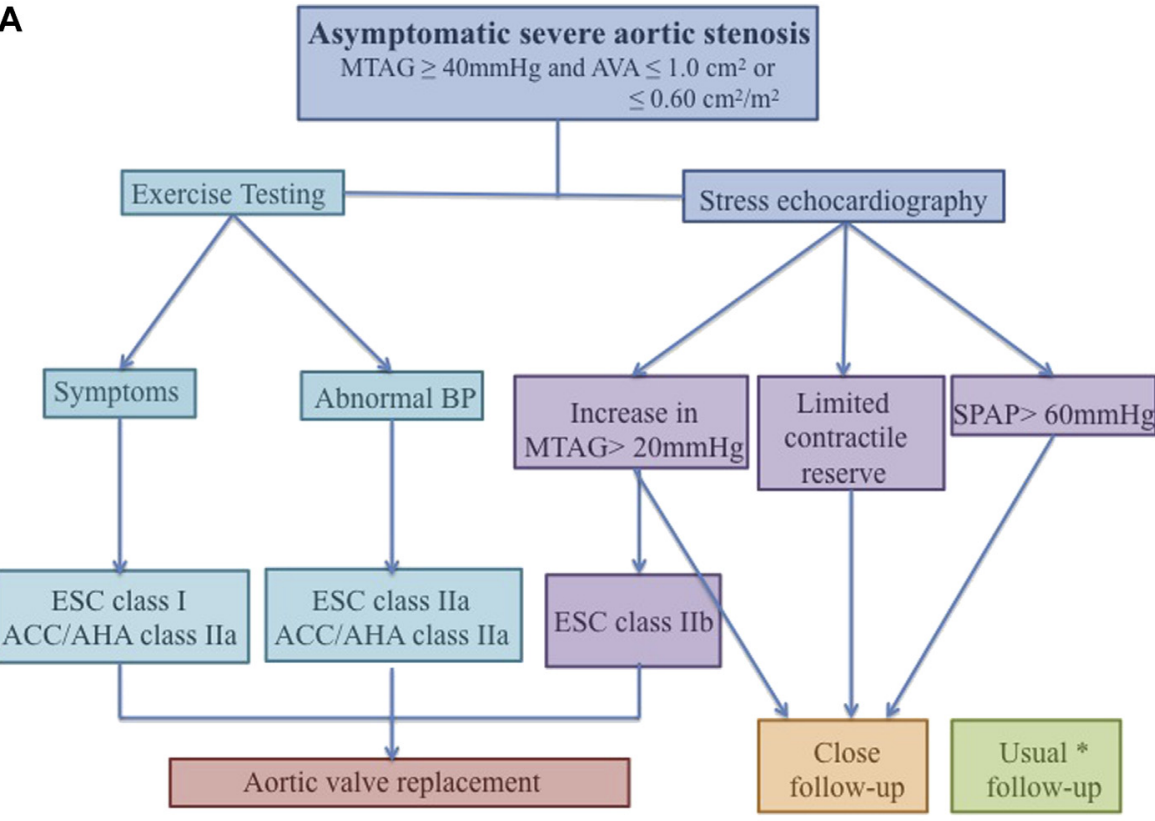

*Patients without criteria of worse prognosis could receive usual follow-up

B

Symptomatic low-flow, low-gradient aortic stenosis AVA $<1.0 \mathrm{~cm}^{2}$ or $<0.6 \mathrm{~cm}^{2} / \mathrm{m}^{2}$ and $\mathrm{MTAG}<30-40 \mathrm{mmHg}$ and $\mathrm{SV}<35 \mathrm{ml} / \mathrm{m}^{2}$

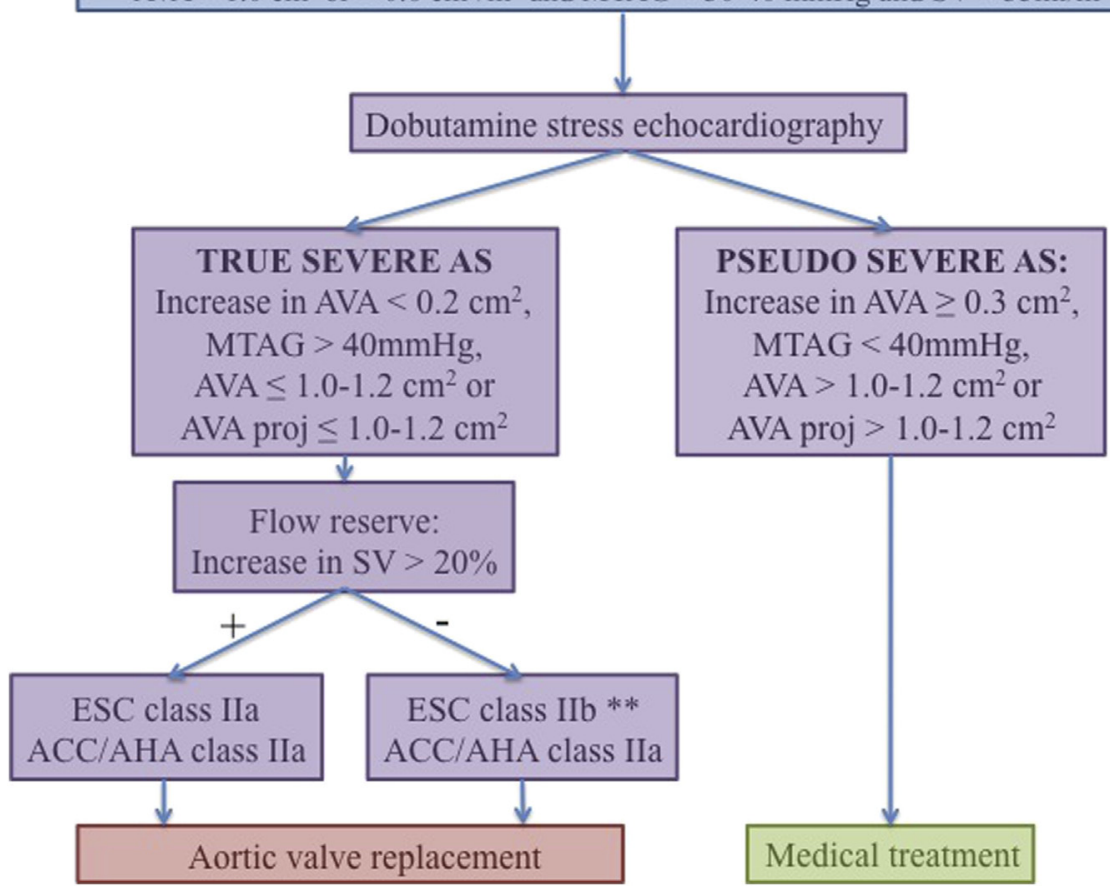

Figure 2. Impact of exercise testing and stress echocardiography in AS on clinical decision-making: asymptomatic severe AS (A) and symptomatic low-flow, low-gradient AS (B). Symptoms include angina, limiting dyspnea, syncope or near-syncope. Abnormal BP is defined as a decrease or $<20$ $\mathrm{mm} \mathrm{Hg}$ increase in systolic BP, and limited contractile reserve as a decrease or limited increase $(<4 \%)$ in LVEF. * Patients without criteria of worse prognosis could receive usual follow-up (ie, every 6 months in ESC/EACTS guidelines or 1 year in ACC/AHA guidelines) vs close follow-up (ie, every 36 months). ** Only in patients with LV dysfunction. ACC/AHA guidelines do not define different levels of recommendations according to presence or absence of flow reserve. ACC/AHA, American College of Cardiology/American Heart Association; AS, aortic stenosis; AVA, aortic valve area; AVA proj, projected AVA; BP, blood pressure; EACTS, European Association of Cardiothoracic Surgery; ESC, European Society of Cardiology; LV, left ventricular; LVEF, LV ejection fraction; MTAG, mean transaortic gradient; SPAP, systolic pulmonary artery pressure; SV, stroke volume. 


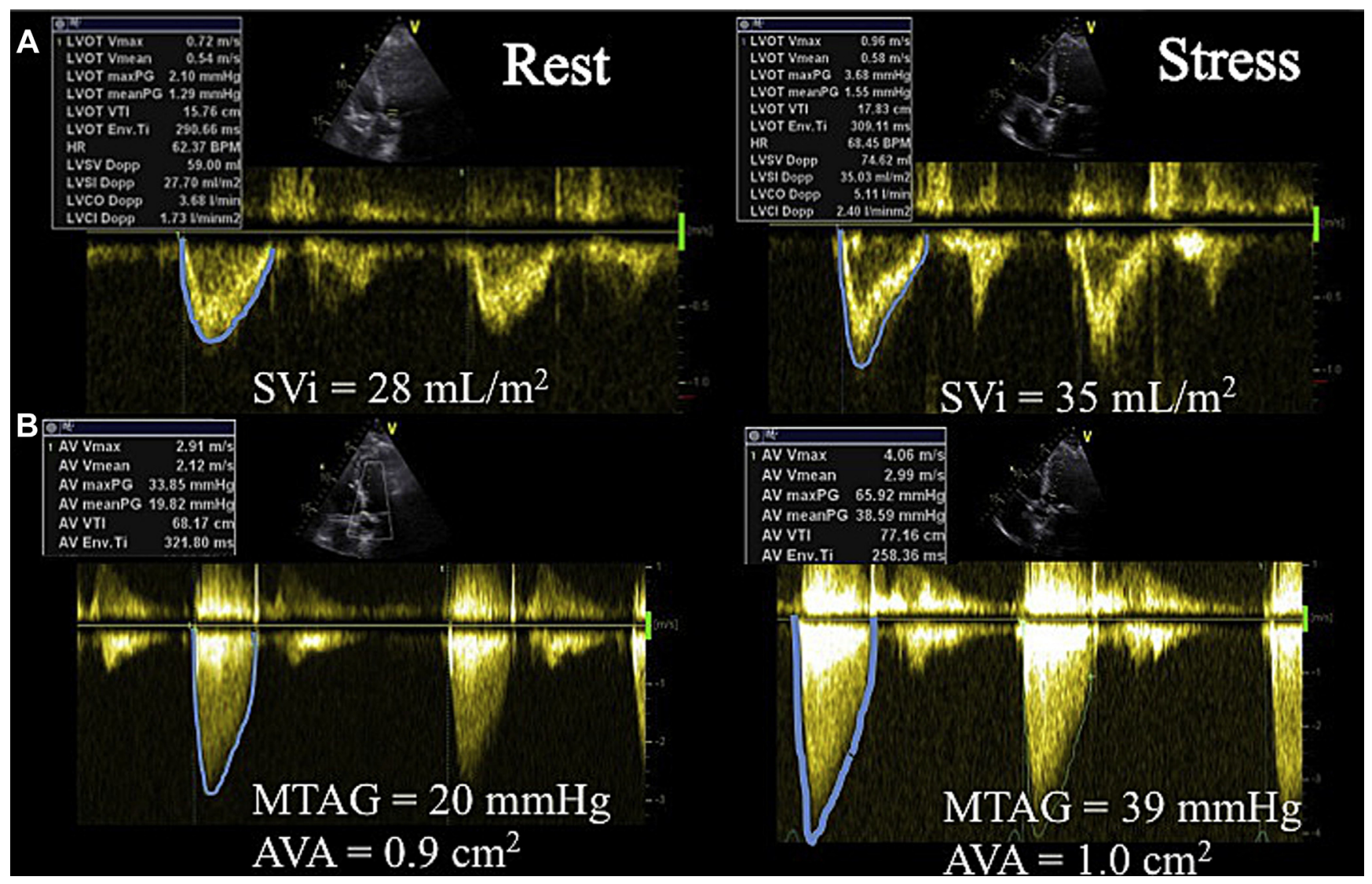

Figure 3. Doppler measurements in a symptomatic patient with low-flow/low-gradient AS. Rest findings (left panels) show low-flow with a SVi of 28 $\mathrm{mL} / \mathrm{m}^{2}$ and low gradient with an MTAG of $19 \mathrm{~mm} \mathrm{Hg}$. At peak dobutamine (right panels), the presence of LV flow reserve (26.5\% increase of SVi) (A), and true severe AS (MTAG = $39 \mathrm{~mm} \mathrm{Hg}$ and AVA $\leq 1.0 \mathrm{~cm}^{2}(\mathbf{B})$ are shown. AS, aortic stenosis; AV, aortic valve; AVA, AV area; Dopp, Doppler; Env. Ti, aortic time interval; HR, heart rate; LV, left ventricular; LVCO, LV cardiac output; LVCI, LV cardiac index; LVOT, LV outflow tract; LVSI, LV stroke index; LVSV, LV stroke volume; maxPG, maximal pressure gradient; meanPG, mean pressure gradient; MTAG, mean transaortic gradient; SVi, stroke volume index; Vmax, maximal velocity; Vmean, mean velocity; VTI, velocity time integral.

\section{Specific situation of low-flow, low-gradient AS with preserved LVEF}

Some patients with severe AS based on calculated AVA might paradoxically present a low-flow, low-gradient condition despite preserved LVEF. This condition, called paradoxical low-flow, low-gradient severe AS, is defined as LVEF $\geq 50 \%$, stroke volume index $\leq 35 \mathrm{~mL} / \mathrm{m}^{2}$, MTAG $<40 \mathrm{~mm} \mathrm{Hg}$, and AVA $<1 \mathrm{~cm}^{2}$ or $<0.6 \mathrm{~cm}^{2} / \mathrm{m}^{2}$, and could be present in up to $25 \%$ of patients with severe AS and preserved LVEF. ${ }^{43}$ This pattern seems to represent a more advanced stage of the disease with a reduced 5-year survival compared with patients with normal-flow, high-gradient severe AS (64\% vs $82 \%$, respectively). AVR is associated with improved survival compared with medical therapy in these patients. ${ }^{44}$ This condition is often misdiagnosed, which leads to the inappropriate delay of surgery. As for patients with low LVEF, low-dose DSE might be useful to unmask pseudosevere AS caused by the lowflow state from true severe AS. Among DSE parameters of AS severity, $\mathrm{AVA}_{\text {proj }} \leq 1 \mathrm{~cm}^{2}$ seems to have the best accuracy to differentiate true from pseudosevere AS and to predict the risk of adverse cardiac events. ${ }^{45}$ Moreover, severe aortic calcification identified using computed tomography might also be helpful to differentiate true vs pseudosevere AS. A threshold of 1651 arbitrary units (AU) or more specifically, $1274 \mathrm{AU}$ for women and $2065 \mathrm{AU}$ for men has been associated with a good sensitivity and specificity $(\geq 80 \%)$ for the diagnosis of true severe AS. ${ }^{40,41}$ Some have suggested that vasodilatory stress catheterization using nitroprusside could be used to identify true severe AS in patients with paradoxical low-flow, low-gradient AS. ${ }^{46}$ More studies are needed to confirm the usefulness of this approach. Recent ESC/EACTS and ACC/AHA guidelines included a class IIa recommendation (Fig. 2B) for AVR in symptomatic patients with paradoxical low-flow, low-gradient severe AS after careful confirmation of true severe AS. ${ }^{1,2}$

\section{Aortic Regurgitation}

\section{Exercise testing}

The occurrence of symptoms in patients with severe aortic regurgitation (AR) is associated with an excessive mortality rate $^{47}$ and represents a strong indication for AVR. ${ }^{1,2}$ Exercise testing is reasonable to unmask symptoms and assess functional capacity in patients with severe AR who present equivocal symptoms. 


\section{Exercise, stress echocardiography, and radionuclide angiography}

Few studies, including those with small numbers of patients, have evaluated the prognostic value of ESE in AR and, routine clinical use is not recommended. If performed, the main goal should be to unmask subclinical LV dysfunction during exercise using standard LVEF measurement or LV longitudinal function assessment with tissue Doppler imaging or 2-dimensional strain. ${ }^{48}$ The demonstration of a limited LV contractile reserve could help to identify patients who might develop progressive LV dysfunction during medical treatment or no improvement in LVEF after AVR. ${ }^{49}$ DSE is almost systematically associated with a decrease in AR severity; it might, however, be useful for the assessment of LV contractile reserve or inducible ischemia. In a cohort of 29 patients with severe AR, preoperative exercise-induced change in LVEF measured using radionuclide ventriculography, compared with preoperative LVEF at rest, has been shown as a predictor of postoperative LV performance during exercise. ${ }^{50}$

\section{Impact on clinical decision-making}

- Although ESE is not recommended for the routine management of AR, measurement of contractile reserve might be useful to unmask subclinical myocardial dysfunction, especially in patients with borderline values of LVEF (50\%-55\%) or end-systolic diameter (near $50 \mathrm{~mm}$ or 25 $\mathrm{mm} / \mathrm{m}^{2}$ ), and might help optimize the timing of surgery. ${ }^{51}$

\section{Mitral Stenosis}

\section{Stress echocardiography}

The clinical utility of stress imaging for MS is limited to echocardiography. The ACC/AHA and ESC/EACTS guidelines recommend stress echocardiography in patients who present a discrepancy between symptoms and severity of MS at rest: (1) to unmask symptoms in asymptomatic patients with at least moderate MS $\left(<1.5 \mathrm{~cm}^{2}\right)$, especially in elderly and/or sedentary patients; and (2) to evaluate the hemodynamic effect of exercise in patients with limiting symptoms, but mild MS. ${ }^{1,2}$ Stress echocardiography can provide important information regarding exercise-induced symptoms, functional capacity, valve function, and its hemodynamic consequences. Exercise stress, being more physiologic, is preferred. Nevertheless, DSE might also be performed and seems to lead to similar hemodynamic changes in mean transmitral gradient (MTMG) and SPAP. ${ }^{52}$ Safety and feasability of DSE have been demonstrated in 53 patients with rheumatic MS. ${ }^{53}$ DSE was started at $10 \mathrm{ug} / \mathrm{kg} / \mathrm{min}$ for 5 minutes and increased by $10 \mathrm{ug} / \mathrm{kg} / \mathrm{min}$ every 3 minutes to a maximal dose of $40 \mathrm{ug} / \mathrm{kg} / \mathrm{min}$. DSE should be performed during usual medical therapy, including $\beta$-adrenergic antagonists. ${ }^{53}$

Changes in mitral gradient and SPAP. Data regarding the use and prognostic value of stress echocardiography in MS are limited. With DSE in patients with at least moderate MS, the increase of MTMG at peak dose was the best predictor of adverses events (hospitalizations, acute pulmonary edema, or supraventricular arrhytmias) during follow-up $(60.5 \pm 11$ months). A cutoff value of $18 \mathrm{~mm} \mathrm{Hg}$ allowed the best detection of events ( $90 \%$ sensitivity and $87 \%$ specificity). ${ }^{53}$ Exercise testing revealed the presence of symptoms in $46 \%$ of 48 "asymptomatic" patients with moderate-severe MS. Of interest, MS severity and SPAP at rest were not different between patients who developed dyspnea during exercise compared with truly asymptomatic patients. The magnitude of exercise-induced increase in MTMG and relative SPAP (exercise/rest SPAP) were significantly greater and more rapid in patients with positive exercise testing (Fig. 4). Also, the cut point of $60 \mathrm{~mm} \mathrm{Hg}$ for exercise SPAP was not significantly related to the occurence of symptoms, but an early exercise-induced increase in relative SPAP $\geq 90 \%$ at 60 $\mathrm{W}$ was associated with a $>2$-fold increase in the risk of developping dyspnea or to require mitral valve intervention during follow-up. These observations suggest that the evaluation of changes in MTMG and the pattern of SPAP progression, especially during the first stage of exercise, play an important role in the evaluation of exercise tolerance and underline the benefits of studying hemodynamic changes at every stage of exercise, rather than simply comparing rest and peak exercise values. ${ }^{54}$

Atrioventricular compliance. Resting and particularly exercise SPAP could be dramatically different in patients with comparable mitral valve areas but different atrioventricular (AtV) compliance. Patients with low $\mathrm{AtV}$ compliance $(\leq 4 \mathrm{~mL} / \mathrm{mm} \mathrm{Hg})$ represent an important clinical entity in which symptoms correspond to severe increases in SPAP during stress. ${ }^{55,56}$ In a study by Brochet et al., AtV compliance was the only independent predictor, among multiple resting echocardiographic parameters, of exercise dyspnea, and an important determinant of functional impairment. ${ }^{54} \mathrm{Net}$ $\mathrm{AtV}$ compliance can be calculated from the ratio of effective mitral valve area (MVA) (continuity equation) and the E-wave downslope: $\mathrm{AtV}$ compliance $(\mathrm{mL} / \mathrm{mm} \mathrm{Hg})=1270$ (MVA $\left[\mathrm{cm}^{2}\right] /$ E-wave downslope $\left.[\mathrm{cm} / \mathrm{s}]\right) .{ }^{55}$

\section{Impact on clinical decision-making}

- When valve anatomy is suitable, percutaneous valvuloplasty may be considered in symptomatic patients with mild MS (MVA $>1.5 \mathrm{~cm}^{2}$ ) and increase in MTMG $>15$ $\mathrm{mm} \mathrm{Hg}$ with exercise (ACC/AHA, class IIb).

- In asymptomatic patients with significant MS (MVA < $1.5 \mathrm{~cm}^{2}$ ), the presence of exercise PHT (SPAP $>60 \mathrm{~mm}$ $\mathrm{Hg}$ ) or increase in MTMG $>15 \mathrm{~mm} \mathrm{Hg}$ should lead to close follow-up.

- Because of the greater operative risk and potential longterm complications with a prosthetic valve, stress echocardiography-related indications do not apply to mitral valve replacement (Fig. 5A).

\section{Primary Mitral Regurgitation}

\section{Exercise, stress echocardiography, and radionuclide angiography}

Primary or organic mitral regurgitation (MR) is a dynamic process. Exercise testing might identify patients with unrecognized symptoms or demystify symptoms that are out of proportion with resting MR severity. Exercise capacity is 


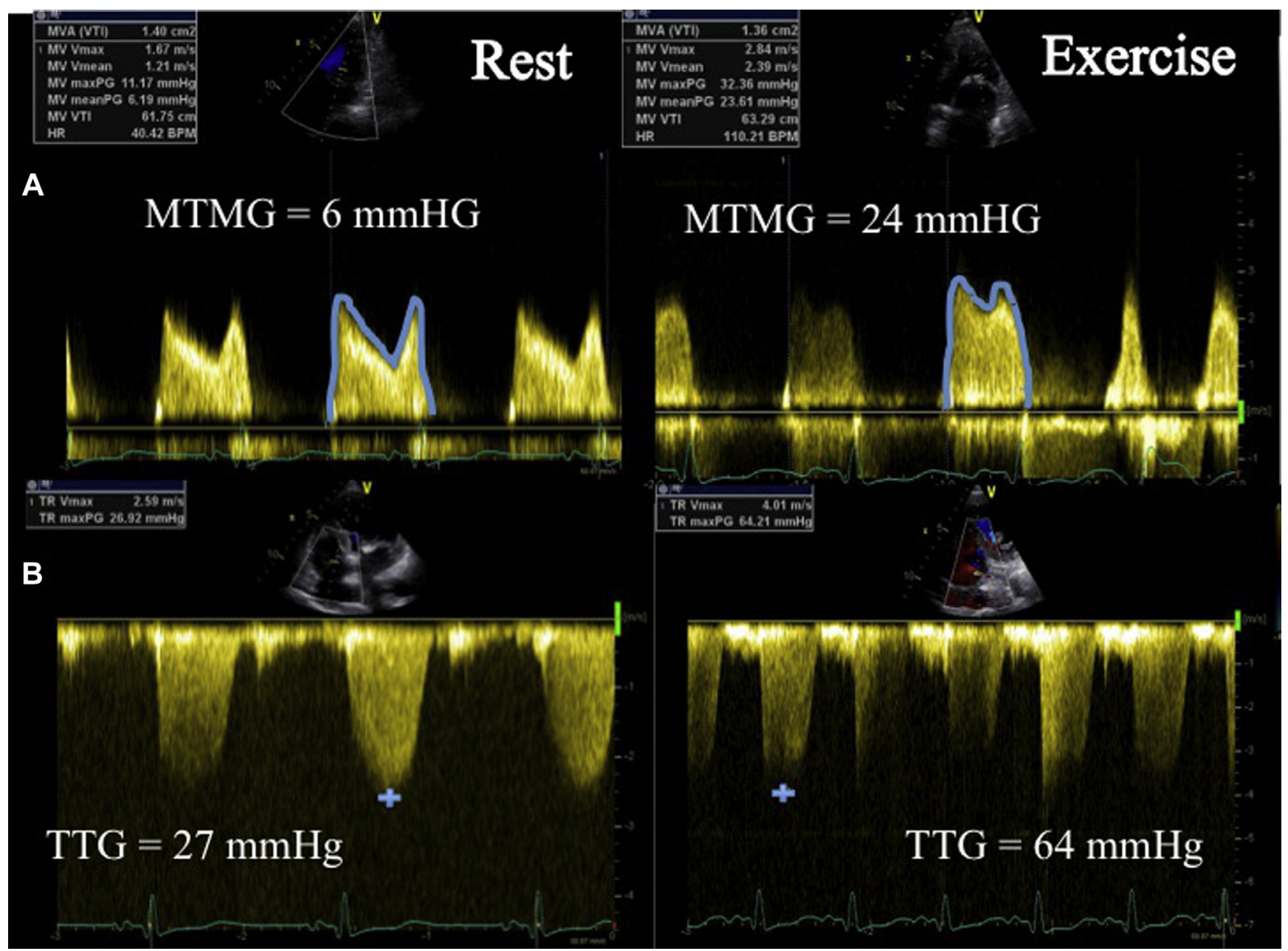

Figure 4. Doppler assessment of an asymptomatic patient with moderate rheumatic mitral stenosis and normal SPAP at rest (left panels). At exercise (right panels), a significant increase in MTMG (A) and PHT (B) are shown. HR, heart rate; maxPG, maximal pressure gradient; meanPG, mean pressure gradient; MTMG, mean transmitral gradient; MV, mitral valve; MVA, MV area; PHT, pulmonary hypertension; SPAP, systolic pulmonary artery pressure; TR, tricuspid regurgitation; TTG, trans-tricuspid gradient; Vmax, maximal velocity; Vmean, mean velocity; VTI, velocity time integral.

markedly reduced in approximately $20 \%$ of asymptomatic patients with severe MR and is associated with worse outcome, regardless of resting MR severity. ${ }^{57}$ ACC/AHA guidelines recommend ESE for asymptomatic severe MR (effective regurgitant orifice area $[\mathrm{EROA}] \geq 40 \mathrm{~mm}^{2}$ and regurgitant volume $[\mathrm{RVol}] \geq 60 \mathrm{~mL}$ ) to establish symptom status and exercise tolerance, and for symptomatic patients where there is a discrepancy between symptoms and the severity of MR at rest (class IIa). ${ }^{1}$ ESE in a semisupine position should be used to evaluate primary MR. DSE is not useful because of the hemodynamic effects leading to decreases of preload and afterload.

Changes in MR severity, SPAP, and right ventricular function. In chronic asymptomatic moderate-severe primary $M R$, a marked exercise-induced increase in MR severity (increase of EROA $\geq 10 \mathrm{~mm}^{2}$ and $\mathrm{RVol} \geq 15 \mathrm{~mL}$ ) was found in one-third of patients and $>50 \%$ of patients with moderate MR at rest developed severe MR during exercise. The magnitude of this increase was well correlated with exerciseinduced PHT, but unrelated to resting MR severity. ${ }^{21}$
Consequently, the main harmful consequence of dynamic MR is the development of exercise-induced PHT. Defined as SPAP $>60 \mathrm{~mm} \mathrm{Hg}$ with exercise, it was present in $46 \%$ of patients and associated with a markedly reduced 2-year symptom-free survival. Moreover, exercise SPAP was a more accurate predictor of progression to symptoms compared with resting SPAP. The best cutoff value of exercise PHT $(>56$ $\mathrm{mm} \mathrm{Hg}$ ) was close to that proposed by guidelines $(>60 \mathrm{~mm}$ $\mathrm{Hg})$. In contrast, the best cutoff value of SPAP at rest $(>36$ $\mathrm{mm} \mathrm{Hg}$ ) was much lower than the value suggested by guidelines $(>50 \mathrm{~mm} \mathrm{Hg}) .{ }^{22}$ Kusunose et al. assessed the role of right ventricular (RV) function during exercise using tricuspid annular plane systolic excursion (TAPSE). They showed that exercise TAPSE was a readily available marker and an independent predictor of time to surgery. Patients with concomitant exercise-induced RV dysfunction (TAPSE $<19$ $\mathrm{mm}$ ) and exercise PHT (SPAP > $54 \mathrm{~mm} \mathrm{Hg}$ ) had the worse prognosis. In multivariate analysis, resting LV strain, RV endsystolic area, exercise SPAP, and exercise TAPSE provided the best predictive model of outcome (Table 2). ${ }^{23}$ Similarly, assessment of RV function at exercise using radionuclide 

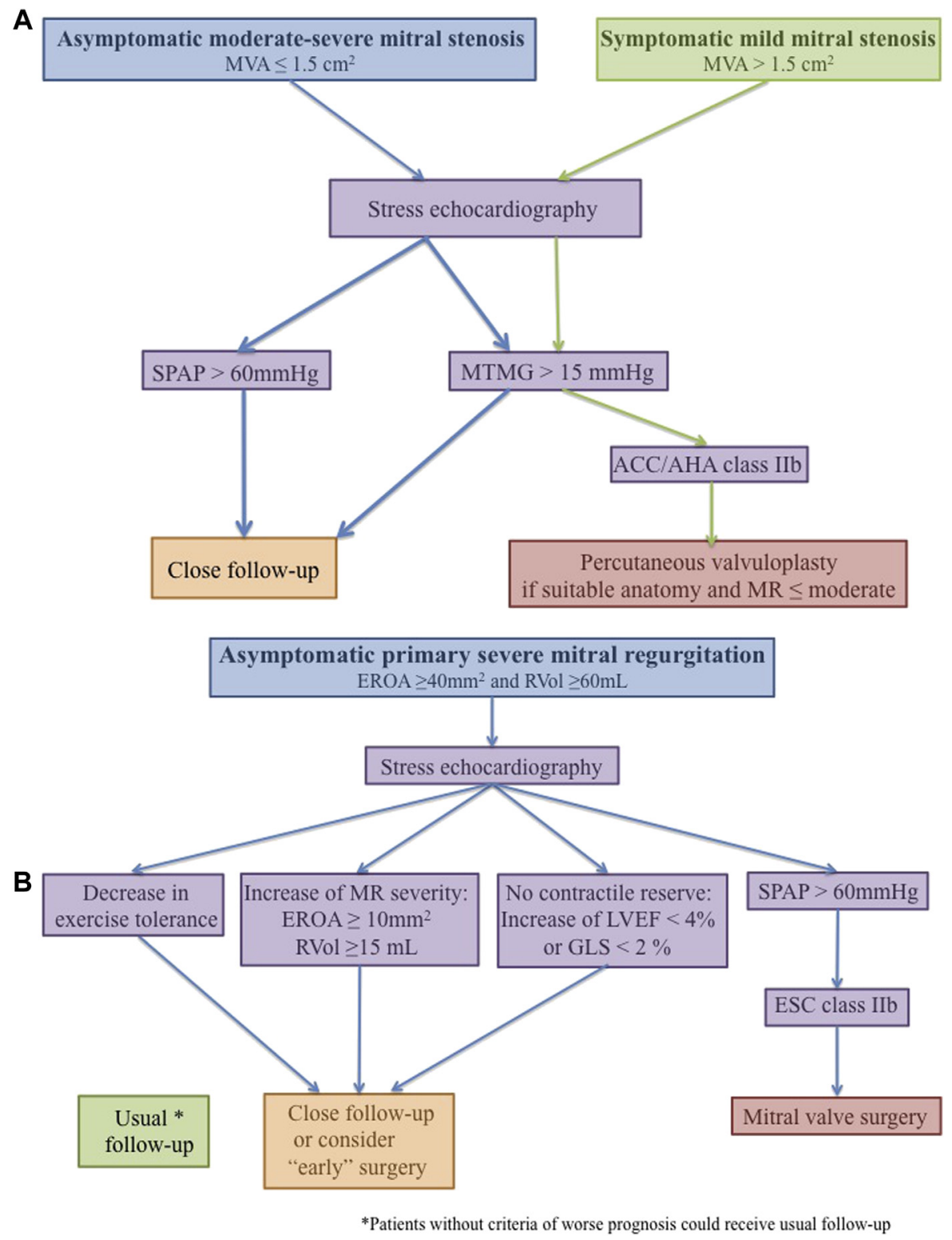

Figure 5. Impact of exercise testing and stress echocardiography on clinical decision-making in mitral valve disease: asymptomatic moderate-severe and asymptomatic mild MS (A), and asymptomatic primary severe MR (B). * Patients without criteria for worse prognosis could receive usual follow-up (every 6 months) vs close follow-up (every 3 months). ACC/AHA, American College of Cardiology/American Heart Association; EROA, effective regurgitant orifice area; ESC, European Society of Cardiology; GLS, global longitudinal strain; LVEF, left ventricular ejection fraction; MR, mitral regurgitation; MS, mitral stenosis; MTMG, mean transmitral gradient; MVA, mitral valve area; RVol, regurgitant volume; SPAP, systolic pulmonary artery pressure.

cineangiography in asymptomatic patients with normal LV and RV function at rest has been shown to predict subsequent development of surgical indications in patients with a decrease in $\mathrm{RV}$ ejection fraction during exercise. ${ }^{58}$

Changes in LV function. ESE is useful to unmask subclinical latent LV dysfunction with MR, especially in cases with borderline LVEF (60\%-65\%) or LV end-systolic diameter (near $40 \mathrm{~mm}$ or $22 \mathrm{~mm} / \mathrm{m}^{2}$ ). ${ }^{4,59}$ Absence of contractile reserve, defined as the inability to increase LVEF by $>4 \%$ or an end-systolic volume index $>25 \mathrm{~cm}^{3} / \mathrm{m}^{2}$ at exercise, has been associated with postoperative LV dysfunction after mitral valve surgery, and progressive deterioration of LV function in medically treated patients. ${ }^{60}$ New tools, such as GLS measured using 2-dimensional speckle-tracking at rest and during exercise, can be used to detect limited contractile reserve and predict postoperative LV dysfunction. GLS measured during exercise has been shown to have greater sensitivity and specificity than exercise LVEF in predicting LV dysfunction (LVEF $<50 \%$ ) after mitral valve surgery. ${ }^{61}$ Moreover, the absence of LV contractile reserve using LV GLS (exercise-induced increase $<2 \%$ ) was significantly associated with higher exercise B-type natriuretic peptide levels and a 2-fold increase in risk of cardiac events. In contrast, there was no significant difference in outcome when LV contractile reserve was assessed using LVEF (Table 2). ${ }^{24,62}$ 


\section{Impact on clinical decision-making}

- In asymptomatic patients with severe primary MR and preserved LVEF, the ESC/EACTS guidelines advocate that surgery is deemed reasonable in patients with SPAP $\geq 60 \mathrm{~mm} \mathrm{Hg}$ during exercise (class IIb recommendations). ${ }^{2}$

- In the debate opposing "early surgery" vs "watchful waiting," ESE might be relevant for risk stratification and estimation of prognosis. Patients with impaired exercise capacity, marked exercise-induced increase in MR or SPAP (as noted herein) and those without LV contractile reserve represent a subset of high-risk patients in whom "early" surgery could be indicated, particularly in a high-volume surgical centre with excellent rates of durable mitral valve repair success. ${ }^{4}$ Conversely, asymptomatic severe MR without any signs of PHT or LV dysfunction during exercise could be safely followedup clinically (Fig. 5B).

\section{Secondary Mitral Regurgitation}

\section{Stress echocardiography}

Mitral valve function is intimately related to LV function and is highly dynamic. Transient myocardial ischemia occasionally causes secondary MR. This can be identified using ESE and often implies significant CAD (usually left circumflex or right coronary stenosis). ${ }^{63}$ In ischemic or dilated cardiomyopathy, complex LV remodelling, including mitral valve and LV geometry deformation, leads to an imbalance between increased tethering forces and reduced closing forces resulting in significant MR and worse prognosis. ${ }^{84,65}$ ESC/EACTS guidelines emphasize the role of ESE to unmask significant dynamic $\mathrm{MR}$ in patients with LV systolic dysfunction. ${ }^{2}$ ESE is recommended in patients with LV dysfunction and: (1) exertional dyspnea out of proportion with the resting MR severity or LVEF; (2) acute pulmonary edema without an obvious cause ${ }^{66}$; (3) moderate MR before surgical revascularization; and (4) for risk stratification of mortality and heart failure. ${ }^{36}$ ESE remains the best modality to evaluate the dynamic component of secondary MR, because DSE leads to confounding effects caused by reduction in loading conditions. DSE might, however, be useful to evaluate myocardial viability and/or ischemia when coronary revascularization concomitant with mitral surgery is contemplated.

\section{Changes in MR severity}

In patients with chronic secondary MR, an EROA $\geq 20$ $\mathrm{mm}^{2}$ at rest should be considered severe because of its effect on cardiac mortality. ${ }^{59}$ Resting MR severity cannot predict the magnitude of exercise-induced increase of MR. ${ }^{67}$ In a cohort of 161 patients with at least mild secondary MR prospectively followed up for $35 \pm 11$ months, an exercise-induced increase in $\mathrm{EROA} \geq 13 \mathrm{~mm}^{2}$ predicted mortality and hospitalization for heart failure. ${ }^{68}$ Exercise-induced increases in EROA and exercise SPAP (Fig. 6) were independently associated with the occurrence of acute pulmonary edema. ${ }^{66}$ The prognostic significance of dynamic MR has not been validated in nonischemic cardiomyopathy.

\section{Impact on clinical decision-making}

- The management of patients with secondary MR is challenging. ${ }^{69}$ For moderate-severe secondary MR and LV dysfunction, coronary disease and myocardial viability should be evaluated to consider revascularization options (ACC/AHA class I). ${ }^{1}$

- Severe secondary MR is not usually improved by revascularization alone and, according to ESC/EACTS and ACC/AHA (class IIa) guidelines, should be addressed during coronary bypass surgery.

- Management of patients with moderate MR is controversial. The ESC/EACTS guidelines recommend the use of ESE to assess dyspnea, MR severity and SPAP (class IIa). ${ }^{2}$

- A significant exercise-induced increase of MR (EROA $\geq$ $13 \mathrm{~mm}^{2}$ ) identifies patients at high risk who could possibly benefit from mitral intervention concomitant with surgical revascularization. Conversely, patients with mild-moderate MR with only mild exercise-induced increase in MR might be treated more conservatively. These recommendations need to be validated in a large prospective trial.

\section{Right-Sided Valvular Heart Disease}

There are no solid data regarding exercise testing or ESE for prognosis or decision-making in right-sided VHD. Cardiovascular magnetic resonance imaging (CMR) has some applications for VHD. ${ }^{70} \mathrm{CMR}$ can identify regional ${ }^{71}$ or diffuse fibrosis ${ }^{72}$ in patients with $\mathrm{AS}$ and evaluate viability before revascularization. ${ }^{73}$ Stress CMR for evaluating VHD is in its early stages of development and has focused on rightsided VHD, relying on imaging techniques used for detection of CAD. ${ }^{74}$ Stress CMR may be performed with either supine ergometer exercise ${ }^{75,76}$ or intravenous inotropes, usually dobutamine using a graded protocol. ${ }^{77,78}$ Ergometer stress CMR is challenging because of motion artifacts.

\section{Pulmonary Stenosis and Regurgitation}

Lurz et al. studied 17 patients with significant pulmonary regurgitation (PR) or stenosis who underwent percutaneous pulmonary valve replacement. ${ }^{76}$ Patients performed supine ergometer (1-2 W increments per minute) before and 1 month after intervention. Real-time CMR images were obtained at rest and every 3 minutes during exercise to measure end-diastolic, end-systolic, and stroke volumes. The study showed that only after percutaneous pulmonary valve replacement could patients with significant PR or pulmonary stenosis increase total stroke volume with exercise. ${ }^{76}$

Roest et al. performed supine ergometer stress CMR at $60 \%$ of peak oxygen consumption in 15 patients with corrected Tetralogy of Fallot and PR. ${ }^{79}$ They observed an abnormal response of the RV during exercise, suggesting that chronic volume overload from PR might have a deleterious effect on RV function. ${ }^{79}$

Valverde et al. performed dobutamine stress CMR in 18 patients with repaired Tetralogy of Fallot and severe PR. ${ }^{77}$ They compared pulmonary valve $\mathrm{RVol}$ and fraction at rest and at stress using volumetric and phase-contrast flow measurements. The authors caution that $\mathrm{RVol}$ and fraction using 


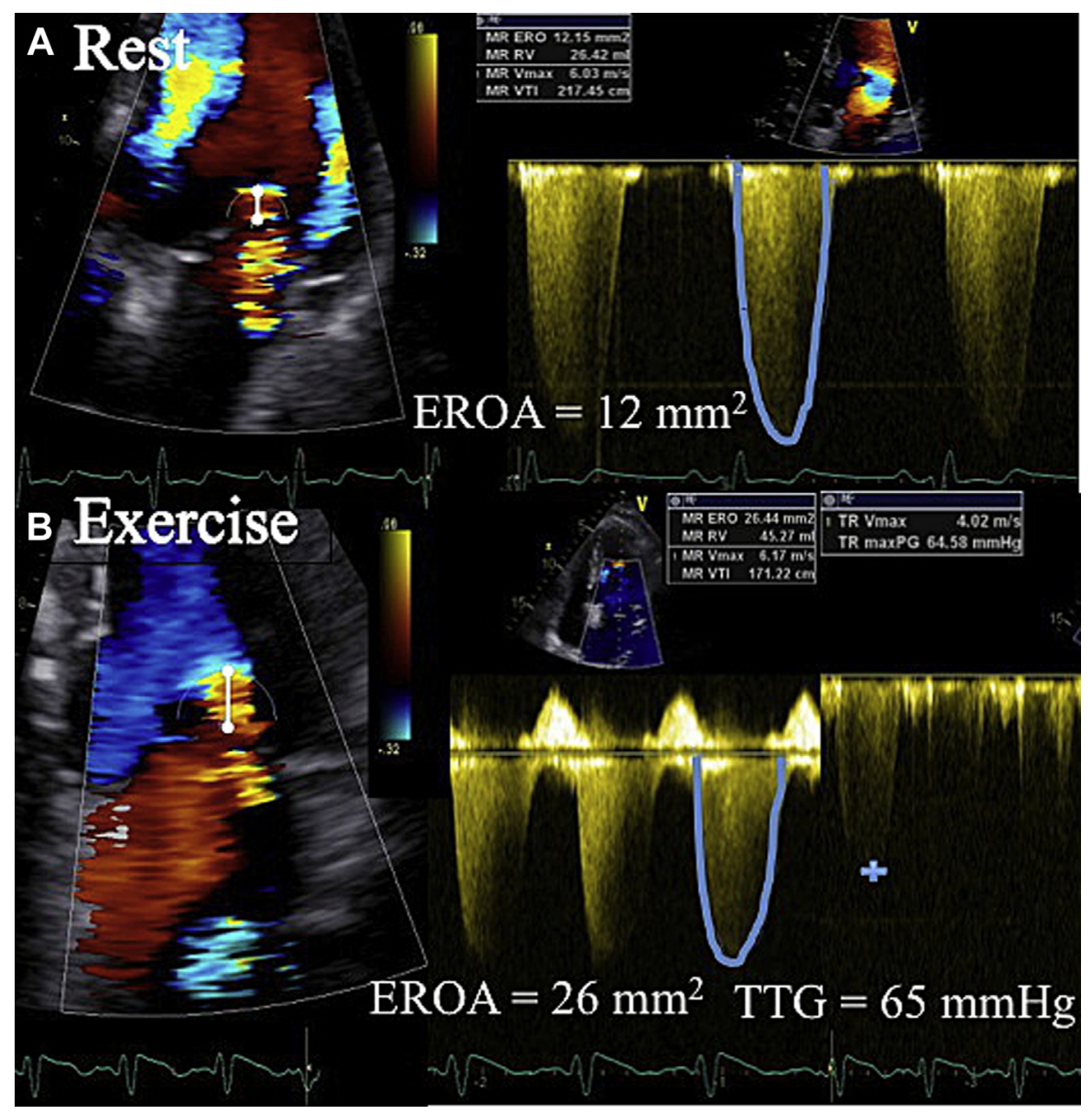

Figure 6. Doppler findings in a symptomatic patient with mild-moderate secondary MR and unmeasurable SPAP because of absence of tricuspid regurgitation at rest $(\mathbf{A})$. With exercise, a significant increase of $\mathrm{MR}\left(\mathrm{ERO} \geq 13 \mathrm{~mm}^{2}\right)$ associated with PHT (B) are shown. ERO, effective regurgitant orifice; EROA, ERO area; maxPG, maximal pressure gradient; MR, mitral regurgitation; PHT, pulmonary hypertension; RV, right ventricular; SPAP, systolic pulmonary artery pressure; TTG, trans-tricuspid gradient; Vmax, maximal velocity; VTI, velocity time integral.

the 2 methods do not have good agreement, especially during stress, and should not be used interchangeably.

Small studies in patients with congenital heart disease indicate that stress CMR is feasible and safe, although it has not yet been shown to influence clinical management. Combination of rest and stress CMR might grow into a comprehensive option for the evaluation of VHD.

\section{Conclusions}

Although the strongest recommendations for surgery continue to be based on symptoms and resting $\mathrm{LV}$ repercussions, recent studies have confirmed the additive prognostic value of the assessment of exercise-induced symptoms and exercise capacity, and evaluation of the dynamic components of VHD using stress imaging, particularly echocardiography. Stress imaging can be useful to optimize risk stratification and timing of surgery in VHD. Randomized clinical trials are required to confirm that clinical decision-making based on stress imaging for VHD leads to improved outcomes.

\section{Funding Sources}

C.H. received grants from the Montreal Heart Institute Foundation (Bourse du Bal du Cœur), the Department of
Medicine of the University of Montreal, and the Association des Cardiologues du Québec, Canada.

\section{Disclosures}

The authors have no conflicts of interest to disclose.

\section{References}

1. Nishimura RA, Otto CM, Bonow RO, et al. 2014 AHA/ACC guideline for the management of patients with valvular heart disease: executive summary: a report of the American College of Cardiology/American Heart Association Task Force on Practice Guidelines. Circulation 2014;129:2440-92.

2. Vahanian A, Alfieri O, Andreotti F, et al. Guidelines on the management of valvular heart disease (version 2012): Joint Task Force on the Management of Valvular Heart Disease of the European Society of Cardiology, European Association for Cardio-Thoracic Surgery. Eur Heart J 2012;33:2451-96.

3. Picano E, Pibarot P, Lancellotti P, Monin JL, Bonow RO. The emerging role of exercise testing and stress echocardiography in valvular heart disease. J Am Coll Cardiol 2009;54:2251-60.

4. Sicari R, Nihoyannopoulos P, Evangelista A, et al. Stress echocardiography expert consensus statement-executive summary: European 
Association of Echocardiography (EAE) (a registered branch of the ESC). Eur Heart J 2009;30:278-89.

5. Pellikka PA, Nagueh SF, Elhendy AA, et al. American Society of Echocardiography recommendations for performance, interpretation, and application of stress echocardiography. J Am Soc Echocardiogr 2007;20: 1021-41.

6. Lancellotti P, Magne J, Pierard LA. The role of stress testing in evaluation of asymptomatic patients with aortic stenosis. Curr Opin Cardiol 2013;28:531-9.

7. Gibbons RJ, Balady GJ, Bricker JT, et al. ACC/AHA 2002 guideline update for exercise testing: summary article: a report of the American College of Cardiology/American Heart Association Task Force on Practice Guidelines (Committee to Update the 1997 Exercise Testing Guidelines). Circulation 2002;106:1883-92.

8. Iung B, Baron G, Butchart EG, et al. A prospective survey of patients with valvular heart disease in Europe: The Euro Heart Survey on Valvular Heart Disease. Eur Heart J 2003;24:1231-43.

9. Monin JL, Lancellotti P, Monchi M, et al. Risk score for predicting outcome in patients with asymptomatic aortic stenosis. Circulation 2009;120:69-75.

10. Amato MC, Moffa PJ, Werner KE, Ramires JA. Treatment decision in asymptomatic aortic valve stenosis: role of exercise testing. Heart 2001;86:381-6

11. Das $\mathrm{P}$, Rimington $\mathrm{H}$, Chambers J. Exercise testing to stratify risk in aortic stenosis. Eur Heart J 2005;26:1309-13.

12. Rafique AM, Biner S, Ray I, et al. Meta-analysis of prognostic value of stress testing in patients with asymptomatic severe aortic stenosis. Am J Cardiol 2009;104:972-7.

13. Brown ML, Pellikka PA, Schaff HV, et al. The benefits of early valve replacement in asymptomatic patients with severe aortic stenosis. J Thorac Cardiovasc Surg 2008;135:308-15.

14. Lancellotti P, Lebois F, Simon M, et al. Prognostic importance of quantitative exercise Doppler echocardiography in asymptomatic valvular aortic stenosis. Circulation 2005;112:1377-82.

15. Marechaux S, Hachicha Z, Bellouin A, et al. Usefulness of exercise-stress echocardiography for risk stratification of true asymptomatic patients with aortic valve stenosis. Eur Heart J 2010;31:1390-7.

16. Leurent G, Donal E, de Place C, et al. Argument for a Doppler echocardiography during exercise in assessing asymptomatic patients with severe aortic stenosis. Eur J Echocardiogr 2009;10:69-73.

17. Lancellotti P, Karsera D, Tumminello G, Lebois F, Pierard LA. Determinants of an abnormal response to exercise in patients with asymptomatic valvular aortic stenosis. Eur J Echocardiogr 2008;9:338-43.

18. Marechaux S, Ennezat PV, LeJemtel TH, et al. Left ventricular response to exercise in aortic stenosis: an exercise echocardiographic study. Echocardiography 2007;24:955-9.

19. Donal E, Thebault C, O'Connor K, et al. Impact of aortic stenosis on longitudinal myocardial deformation during exercise. Eur J Echocardiogr 2011;12:235-41.

20. Lancellotti P, Magne J, Donal E, et al. Determinants and prognostic significance of exercise pulmonary hypertension in asymptomatic severe aortic stenosis. Circulation 2012;126:851-9.

21. Magne J, Lancellotti P, Pierard LA. Exercise-induced changes in degenerative mitral regurgitation. J Am Coll Cardiol 2010;56:300-9.
22. Magne J, Lancellotti P, Pierard LA. Exercise pulmonary hypertension in asymptomatic degenerative mitral regurgitation. Circulation 2010;122: $33-41$.

23. Kusunose K, Popovic ZB, Motoki H, Marwick TH. Prognostic significance of exercise-induced right ventricular dysfunction in asymptomatic degenerative mitral regurgitation. Circ Cardiovasc Imaging 2013;6: $167-76$.

24. Magne J, Mahjoub H, Dulgheru R, Pibarot P, Pierard LA, Lancellotti P. Left ventricular contractile reserve in asymptomatic primary mitral regurgitation. Eur Heart J 2014;35:1608-16.

25. Lancellotti P, Donal E, Magne J, et al. Risk stratification in asymptomatic moderate to severe aortic stenosis: the importance of the valvular, arterial and ventricular interplay. Heart 2010;96:1364-71.

26. Lafitte $S$, Perlant $M$, Reant $P$, et al. Impact of impaired myocardial deformations on exercise tolerance and prognosis in patients with asymptomatic aortic stenosis. Eur J Echocardiogr 2009;10:414-9.

27. Lancellotti P, Moonen M, Magne J, et al. Prognostic effect of long-axis left ventricular dysfunction and B-type natriuretic peptide levels in asymptomatic aortic stenosis. Am J Cardiol 2010;105:383-8.

28. Bruch C, Stypmann J, Grude M, et al. Tissue Doppler imaging in patients with moderate to severe aortic valve stenosis: clinical usefulness and diagnostic accuracy. Am Heart J 2004;148:696-702.

29. Pibarot P, Dumesnil JG. Low-flow, low-gradient aortic stenosis with normal and depressed left ventricular ejection fraction. J Am Coll Cardiol 2012;60:1845-53.

30. deFilippi CR, Willett DL, Brickner ME, et al. Usefulness of dobutamine echocardiography in distinguishing severe from nonsevere valvular aortic stenosis in patients with depressed left ventricular function and low transvalvular gradients. Am J Cardiol 1995;75:191-4.

31. Monin JL, Monchi M, Gest V, et al. Aortic stenosis with severe left ventricular dysfunction and low transvalvular pressure gradients: risk stratification by low-dose dobutamine echocardiography. J Am Coll Cardiol 2001;37:2101-7.

32. Monin JL, Quere JP, Monchi M, et al. Low-gradient aortic stenosis: operative risk stratification and predictors for long-term outcome: a multicenter study using dobutamine stress hemodynamics. Circulation 2003;108:319-24

33. Schwammenthal E, Vered Z, Moshkowitz Y, et al. Dobutamine echocardiography in patients with aortic stenosis and left ventricular dysfunction: predicting outcome as a function of management strategy. Chest 2001;119:1766-77.

34. Blais C, Burwash IG, Mundigler G, et al. Projected valve area at normal flow rate improves the assessment of stenosis severity in patients with low-flow, low-gradient aortic stenosis: the multicenter TOPAS (Truly or Pseudo-Severe Aortic Stenosis) study. Circulation 2006;113:711-21.

35. Clavel MA, Fuchs C, Burwash IG, et al. Predictors of outcomes in lowflow, low-gradient aortic stenosis: results of the multicenter TOPAS Study. Circulation 2008;118:S234-42.

36. Pierard LA, Lancellotti P. Stress testing in valve disease. Heart 2007;93: 766-72.

37. Fougeres E, Tribouilloy C, Monchi M, et al. Outcomes of pseudo-severe aortic stenosis under conservative treatment. Eur Heart J 2012;33: 2426-33.

38. Tribouilloy C, Levy F, Rusinaru D, et al. Outcome after aortic valve replacement for low-flow/low-gradient aortic stenosis without contractile reserve on dobutamine stress echocardiography. J Am Coll Cardiol 2009;53:1865-73. 
39. Quere JP, Monin JL, Levy F, et al. Influence of preoperative left ventricular contractile reserve on postoperative ejection fraction in lowgradient aortic stenosis. Circulation 2006;113:1738-44.

40. Cueff C, Serfaty JM, Cimadevilla C, et al. Measurement of aortic valve calcification using multislice computed tomography: correlation with haemodynamic severity of aortic stenosis and clinical implication for patients with low ejection fraction. Heart 2011;97:721-6.

41. Clavel MA, Messika-Zeitoun D, Pibarot P, et al. The complex nature of discordant severe calcified aortic valve disease grading: new insights from combined Doppler-echocardiographic and computed tomographic study. J Am Coll Cardiol 2013;62:2329-38.

42. Clavel MA, Burwash IG, Mundigler G, et al. Validation of conventional and simplified methods to calculate projected valve area at normal flow rate in patients with low flow, low gradient aortic stenosis: the multicenter TOPAS (True or Pseudo Severe Aortic Stenosis) study. J Am Soc Echocardiogr 2010;23:380-6.

43. Hachicha Z, Dumesnil JG, Bogaty P, Pibarot P. Paradoxical low-flow, low-gradient severe aortic stenosis despite preserved ejection fraction is associated with higher afterload and reduced survival. Circulation 2007;115:2856-64.

44. Clavel MA, Dumesnil JG, Capoulade R, et al. Outcome of patients with aortic stenosis, small valve area, and low-flow, low-gradient despite preserved left ventricular ejection fraction. J Am Coll Cardiol 2012;60: 1259-67.

45. Clavet MA, Ennezat PV, Marechaux S, et al. Stress echocardiography to assess stenosis severity and predict outcome in patients with paradoxical low-flow, low-gradient aortic stenosis and preserved LVEF. JACC Cardiovasc Imaging 2013;6:175-83.

46. Nishimura RA, Carabello BA. Hemodynamics in the cardiac catheterization laboratory of the 21st century. Circulation 2012;125:2138-50.

47. Dujardin KS, Enriquez-Sarano M, Schaff HV, et al. Mortality and morbidity of aortic regurgitation in clinical practice. A long-term followup study. Circulation 1999;99:1851-7.

48. Vinereanu D, Ionescu AA, Fraser AG. Assessment of left ventricular long axis contraction can detect early myocardial dysfunction in asymptomatic patients with severe aortic regurgitation. Heart 2001;85:30-6.

49. Wahi S, Haluska B, Pasquet A, et al. Exercise echocardiography predicts development of left ventricular dysfunction in medically and surgically treated patients with asymptomatic severe aortic regurgitation. Heart 2000;84:606-14.

50. Tamas E, Broqvist M, Olsson E, Franzen S, Nylander E. Exercise radionuclide ventriculography for predicting post-operative left ventricular function in chronic aortic regurgitation. JACC Cardiovascular Imaging 2009;2:48-55.

51. Lancellotti P, Tribouilloy C, Hagendorff A, et al. European Association of Echocardiography recommendations for the assessment of valvular regurgitation. Part 1: aortic and pulmonary regurgitation (native valve disease). Eur J Echocardiogr 2010;11:223-44.

52. Hecker SL, Zabalgoitia M, Ashline P, et al. Comparison of exercise and dobutamine stress echocardiography in assessing mitral stenosis. Am J Cardiol 1997;80:1374-7.

53. Reis G, Motta MS, Barbosa MM, et al. Dobutamine stress echocardiography for noninvasive assessment and risk stratification of patients with rheumatic mitral stenosis. J Am Coll Cardiol 2004;43:393-401.

54. Brochet E, Detaint D, Fondard O, et al. Early hemodynamic changes versus peak values: what is more useful to predict occurrence of dyspnea during stress echocardiography in patients with asymptomatic mitral stenosis? J Am Soc Echocardiogr 2011;24:392-8.
55. Schwammenthal E, Vered Z, Agranat O, et al. Impact of atrioventricular compliance on pulmonary artery pressure in mitral stenosis: an exercise echocardiographic study. Circulation 2000;102:2378-84.

56. Li M, Dery JP, Dumesnil JG, et al. Usefulness of measuring net atrioventricular compliance by Doppler echocardiography in patients with mitral stenosis. Am J Cardiol 2005;96:432-5.

57. Messika-Zeitoun D, Johnson BD, Nkomo V, et al. Cardiopulmonary exercise testing determination of functional capacity in mitral regurgitation: physiologic and outcome implications. J Am Coll Cardiol 2006;47: 2521-7.

58. Borer JS, Hochreiter C, Rosen S. Right ventricular function in severe non-ischaemic mitral insufficiency. Eur Heart J 1991;12(suppl B):22-5.

59. Lancellotti P, Moura L, Pierard LA, et al. European Association of Echocardiography recommendations for the assessment of valvular regurgitation. Part 2: mitral and tricuspid regurgitation (native valve disease). Eur J Echocardiogr 2010;11:307-32.

60. Lee R, Haluska B, Leung DY, et al. Functional and prognostic implications of left ventricular contractile reserve in patients with asymptomatic severe mitral regurgitation. Heart 2005;91:1407-12.

61. Lancellotti P, Cosyns B, Zacharakis D, et al. Importance of left ventricular longitudinal function and functional reserve in patients with degenerative mitral regurgitation: assessment by two-dimensional speckle tracking. J Am Soc Echocardiogr 2008;21:1331-6.

62. Magne J, Mahjoub H, Pibarot P, et al. Prognostic importance of exercise brain natriuretic peptide in asymptomatic degenerative mitral regurgitation. Eur J Heart Fail 2012;14:1293-302.

63. Lancellotti P, Marwick T, Pierard LA. How to manage ischaemic mitral regurgitation. Heart 2008;94:1497-502.

64. Grigioni F, Enriquez-Sarano M, Zehr KJ, Bailey KR, Tajik AJ. Ischemic mitral regurgitation: long-term outcome and prognostic implications with quantitative Doppler assessment. Circulation 2001;103:1759-64.

65. Grigioni F, Detaint D, Avierinos JF, et al. Contribution of ischemic mitral regurgitation to congestive heart failure after myocardial infarction. J Am Coll Cardiol 2005;45:260-7.

66. Pierard LA, Lancellotti P. The role of ischemic mitral regurgitation in the pathogenesis of acute pulmonary edema. N Engl J Med 2004;51: 1627-34.

67. Lancellotti P, Lebrun F, Pierard LA. Determinants of exercise-induced changes in mitral regurgitation in patients with coronary artery disease and left ventricular dysfunction. J Am Coll Cardiol 2003;42:1921-8.

68. Lancellotti P, Gerard PL, Pierard LA. Long-term outcome of patients with heart failure and dynamic functional mitral regurgitation. Eur Heart J 2005;26:1528-32.

69. Levine RA, Schwammenthal E. Ischemic mitral regurgitation on the threshold of a solution: from paradoxes to unifying concepts. Circulation 2005;112:745-58.

70. Cawley PJ, Maki JH, Otto CM. Cardiovascular magnetic resonance imaging for valvular heart disease: technique and validation. Circulation 2009;119:468-78.

71. Rudolph A, Abdel-Aty H, Bohl S, et al. Noninvasive detection of fibrosis applying contrast-enhanced cardiac magnetic resonance in different forms of left ventricular hypertrophy relation to remodeling. J Am Coll Cardiol 2009;53:284-91.

72. Flett AS, Hayward MP, Ashworth MT, et al. Equilibrium contrast cardiovascular magnetic resonance for the measurement of diffuse 
myocardial fibrosis: preliminary validation in humans. Circulation 2010;122:138-44.

73. Kim RJ, Wu E, Rafael A, et al. The use of contrast-enhanced magnetic resonance imaging to identify reversible myocardial dysfunction. $\mathrm{N}$ Engl J Med 2000;343:1445-53.

74. Lipinski MJ, McVey CM, Berger JS, Kramer CM, Salerno M. Prognostic value of stress cardiac magnetic resonance imaging in patients with known or suspected coronary artery disease: a systematic review and meta-analysis. J Am Coll Cardiol 2013;62:826-38.

75. Raman SV, Dickerson JA, Jekic M, et al. Real-time cine and myocardial perfusion with treadmill exercise stress cardiovascular magnetic resonance in patients referred for stress SPECT. J Cardiovasc Magn Reson 2010; $12: 41$.
76. Lurz P, Muthurangu V, Schuler PK, et al. Impact of reduction in right ventricular pressure and/or volume overload by percutaneous pulmonary valve implantation on biventricular response to exercise: an exercise stress real-time CMR study. Eur Heart J 2012;33:2434-41.

77. Valverde I, Parish V, Tzifa A, et al. Cardiovascular MR dobutamine stress in adult tetralogy of Fallot: disparity between CMR volumetry and flow for cardiovascular function. J Magn Reson Imaging 2011;33:1341-50.

78. Nagel E, Lehmkuhl HB, Bocksch W, et al. Noninvasive diagnosis of ischemia-induced wall motion abnormalities with the use of high-dose dobutamine stress MRI: comparison with dobutamine stress echocardiography. Circulation 1999;99:763-70.

79. Roest AA, Helbing WA, Kunz P, et al. Exercise MR imaging in the assessment of pulmonary regurgitation and biventricular function in patients after tetralogy of fallot repair. Radiology 2002;223:204-11. 